\title{
重症頭部外傷患者管理における $30^{\circ}$ 頭位挙上の有用性 一特に頭蓋内コンプライアンスの低い症例においてー
}

\author{
吉原成哲 佐 藤 潔 Anthony Marmarou*
}

\section{The Effect of $30^{\circ}$ Head Elevation in Severe Head Injured Patients}

by

\author{
Masaaki Yoshihara, M.D., Kiyoshi Sato, M.D., and Anthony Marmarou, Ph.D.* \\ from
}

Department of Neurosurgery, Juntendo University School of Medicine, and ${ }^{*}$ Division of Neurosurgery, Medical College of Virginia, U.S. A.

The positioning of intracranial hypertensive patients for treatment of intracranial pressure (ICP) and cerebral perfusion pressure (CPP) varies among institutions and the optimal grade of head elevation is still under discussion. Reductions in intracranial pressure at head elevation have been noted both experimentally and clinically. However, since the reports suggested that CPP is a better predictor of outcome than ICP and that patients with a CPP of less than $40 \mathrm{mmHg}$ have a poor prognosis regardless of ICP, we have to take CPP into consideration. The purpose of this study was to investigate the effect on the ICP, CPP and Pressure Volume Index (PVI) of $30^{\circ}$ head elevated position in severely head injured patients.

Twenty three severely head injured patients $(\mathrm{GCS} \leq 8)$ were involved in this study. All patients remained intubated, paralyzed and mechanically ventilated during the study. ICP was measured by fluid filled ventricular catheter connecting to a bedside monitor and the radial artery was cannulated for blood pressure measurement. The transducer level of both ICP and blood pressure were always referred to foramen of Monro. The CPP was calculated by the following equation : $\mathrm{CPP}=$ mean $\mathrm{BP}-$ mean ICP. Patients were positioned at $0^{\circ}$ head elevation first, then elevated to $30^{\circ}$ and returned to $0^{\circ}$ head elevation again. Each position was maintained for exactly 15 minutes. Thirty two studies were performed among 23 patients. PVI at $0^{\circ}$ head elevation were obtained in all patients and PVI at $30^{\circ}$ head elevation were obtained in 10 patients after 15 minutes head elevation. At the $30^{\circ}$ head elevation, ICP was decreased in each study, however CPP was altered differently. Of the 32 studies were performed, the CPP of 12 studies were increased or remained unchanged and the CPP of 20 studies were decreased. The PVI was statistically lower in the patients whose $\mathrm{CPP}$ were increased or remained unchanged at $30^{\circ}$ head elevation. We concluded that $30^{\circ}$ head elevation benefits the patients those who have a tight brain (low PVI). Our data also showed that PVI was not altered by $30^{\circ}$ head elevation, suggesting brain compliance remains stable during position change.

(Received February 17, 1994 ; accepted May 17, 1994)

Key words : severe head injury, $30^{\circ}$ head elevation, intracranial pressure (ICP), cerebral perfusion pressure $(\mathrm{CPP})$, pressure volume index (PVI)

Jpn J Neurosurg (Tokyo) $3: 515-521,1994$

順天堂大学医学部脳神経外科 $/ \bar{\top} 112$ 文京区本郷 2-1-1〔連絡先：吉原成哲〕

Address reprint request to : Masaaki Yoshihara, M.D., Department of Neurosurgery, Juntendo University School of Medicine, Hongo 2-1-1, Bunkyo-ku 113, Tokyo, Japan

*Division of Neurosurgery, Medical College of Virginia, U. S. A. 


\section{緒 言}

頭蓋内圧 (ICP) 方進を伴う重症頭部外傷患者の管理 に際し, 脳灌流圧 (CPP) を正常範囲内に維持しつつ頭 蓋内圧を下降せしめることは, 治療上きわめて重要な事 項である1217). しかし，これを達成するための最も効果 的と思われる患者の体位は各施設でまちまちであり，頭 位を水平位とするか挙上するかいまだ議論の分かれると ころである. Woischneck ら ${ }^{23) や D ~ D u r w a r d ~ ら 21 は ， 30 ~}$ までの頭位挙上では頭蓋内圧は常に低下したが，脳灌流 圧は低下せず保たれていたと報告している。他方 Rosner ら ${ }^{15)}$ は, 最大の脳灌流圧を得るために患者の体 位は水平位とすべきであると主張しており，頭位挙上に よる脳灌流圧の低下が pressure wave を起こす引きが ねとなっていると報告している。最後に March ら ${ }^{8)}$ は, 体位変化に起因する脳灌流圧の変化は一定でなく, 個々 の患者で違った変化を示すと報告した。以上より，頭蓋 内圧六進を伴った患者管理に扔いて，体位に関して以下 のごとく 3 つの異なった意見が出されている. (1) $30^{\circ}$ 頭 位挙上を保つ (Woischneck, Durward). (2) 頭部を含め 水平位を保つ (Rosner). (3) 頭位挙上による頭蓋内圧, 脳灌流圧の反応を個々の症例で確認し，その結果で判定 する(March)。これらの報告をふまえ，われわれは急性 期の重症頭部外傷患者（GCS 8以下）を治療するにあた り，患者の体位を頭部を含め水平位とするか，あるいは 頭位を $30^{\circ}$ 挙上すべきかを, 頭蓋内圧, 血圧, 脳灌流圧お よび PVI (Pressure Volume Index) を測定し検討した。 また $30^{\circ}$ 頭位挙上にて頭蓋内コンプライアンスがどう変 化するか, 水平位および $30^{\circ}$ 頭位挙上時の PVI を測定し, 比較検討した。

\section{方法および症例}

\section{Patients population and prepara- tions}

対象は 1989 年 10 月〜 1992 年 1 月まで Medical College of Virginia の Neuroscience Intensive Care Unit に入院した Glasgow Coma Scale 8 以下の重症頭部外傷 患者 23 例である。全症例のまとめを Table 1 に示す。 gunshot wound や䯣液漏を伴った症例，および脳死の判 定基準を満たした症例は, 本研究の対象より除外した。 全例に気管内挿管を施行し，筋弛緩剂を投与し，呼吸を 完全な人工管理とした。頭蓋内圧は側脳室で，血圧は橈 骨動脈で測定した。本臨床研究は, Medical College of Virginiaに抢ける The Committee on the Conduct of
Table 1 Summary of patients in this study

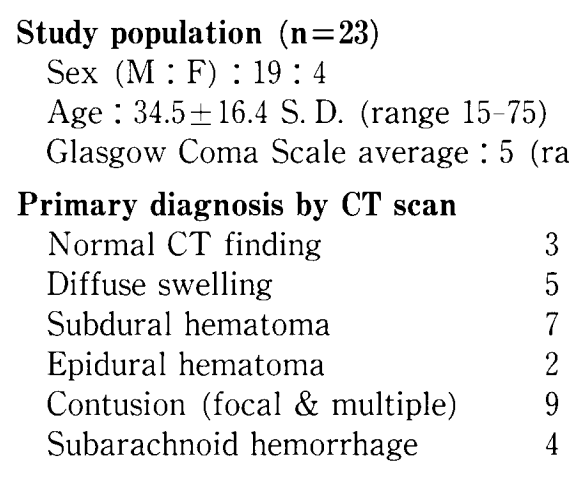

Human Researchにより承認されており，検查前に全例 の家族より紙面で同意を得ている。なお検査は受傷後 5 日以内の急性期において施行した。

\section{Protocol of position change}

検査開始 15 分前に十分な鎮静剂 (Morphine $10 \mathrm{mg}$, IV) および筋弛緩剤 (Bacuroniume $10 \mathrm{mg}$, IV) を投与 し, 患者の体動や咳嗽反射による頭蓋内圧, 血圧の変動 を極力抑えた。まず水平位で PVI を測定した後, 体位を 水平位に 15 分間, 次いで頭位挙上 $30^{\circ}$ を 15 分間維持し, 再び水平位に戻した，頭蓋内圧抢よび血圧の水準点は体 位のいかんにかかわらずモンロー孔とし，それぞれの デー夕は $20 \mathrm{~Hz}$ の頻度でコンピュー夕に連続的に記録 した。体位変換後ほほ 10 分が経過した安定した状態の頭 蓋内压抢よび血圧を選出し，おのおの 5 分間の平均值を とり，それぞれの体位の頭蓋内圧，血圧とし，脳灌流圧 を算出した。合計 23 症例中で, 16 症例においては 1 回の みの検查を，他の 5 症例では 2 回， 2 症例では 3 回の検 查をそれぞれ日時を変えて施行し, 計 32 回の検査を行っ た。

\section{Measurement of PVI}

全例において水平位の PVI を測定し，そのうちの 10 症例に対しては $30^{\circ}$ 頭位挙上 15 分後にも PVI を測定し た.PVIは Marmarou らの方法に従い，側脳室内に入 れたカテーテルを通し，一定量の髄液や生食を排出また は注入し, その結果起こる頭蓋内压の変化を測定するこ とにより得ることができる11)。すなわち Withdrawal PVI (PVIw) は $1 \sim 2 \mathrm{~m} l$ の䯋液を側脳室より排除させ ることによって次式より算出できる.

$$
\mathrm{PVIw}=\mathrm{V} / \log (\mathrm{Po} / \mathrm{Pp})
$$

ここで V は排除せしめた髄液量, Po は髄液排除前の頭 蓋内圧, $\mathrm{Pp}$ は髄液排除直後の頭蓋内圧である. 同様に Injection PVI (PVIi) は $1 \sim 2 \mathrm{~m} l$ の生食を側脳室内に 


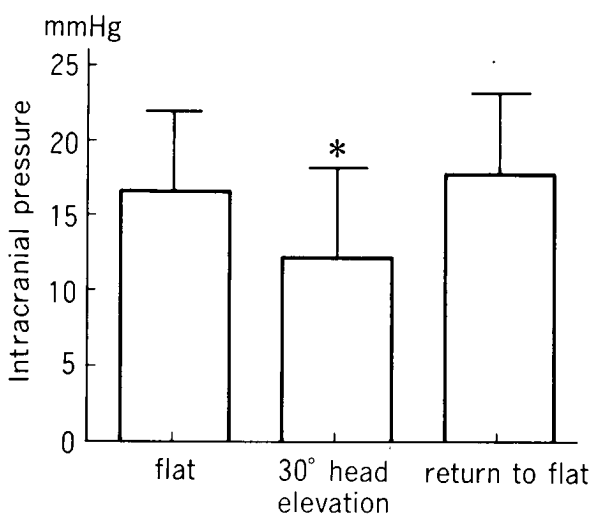

Fig. 1 At the haed elevation of $30^{\circ}$, the average intracranial pressure fell $16.6 \mathrm{mmHg}$ to $12.2 \mathrm{mmHg}$.

*The paired Student-T test showed the intracranial pressure change was statistical significant $(\mathrm{p}<0.01)$.

注入することによって次式より算出できる. $\mathrm{PVIi}=\mathrm{V} / \log (\mathrm{Pn} / \mathrm{Pm})$

ここでVは注入した生食量, $\mathrm{Pn}$ は生食注入直後の上昇 した頭蓋内圧, Pm は生食注入前の基礎圧である. 脳室 内へ生食の injection や髄液の withdraw により本来の 頭蓋内圧が変化するのを最小限にするため, PVIw と PVIi を各 1 回ずつ施行し，その平均値を使用した。

\section{結 果}

\section{$130^{\circ}$ 頭位挙上の頭蓋内圧に及ぼす影響}

$30^{\circ}$ 頭位挙上にて頭蓋内圧は 2 例の不変を除くと全例 で低下し，上昇した症例は 1 例もなかった。水平位扔よ び $30^{\circ}$ 頭位挙上時における頭蓋内圧の全測定例の平均值 の変化を Fig. 1 に示す。水平位に扔ける全症例の頭蓋内 圧の平均值は $16.6 \pm 5.19 \mathrm{mmHg}$ であり, $30^{\circ}$ 頭位挙上に て $12.2 \pm 5.88 \mathrm{mmHg}$ と有意に低下し (paired Student - T test $: \mathrm{p}<0.01)$, 再び水平位にすると $17.6 \pm 5.60$ $\mathrm{mmHg}$ とほぼ元の頭蓋内圧に復帰した。

\section{$230^{\circ}$ 頭位挙上の血圧に及ぼす影響}

水平位, $30^{\circ}$ 頭位挙上時に抢ける血圧の全測定例の平均 值を Fig. 2 に示す. 水平位における血圧の平均値は 96.5 $\pm 16.40 \mathrm{mmHg}$ であるが， $30^{\circ}$ 頭位挙上にて $89.5 \pm 17.60$ $\mathrm{mmHg}$ と統計的に有意に低下し (paired Student-T test : $\mathrm{p}<0.01)$, 再び水平位にすると $96.9 \pm 15.20 \mathrm{mmHg}$ とほほ元の血圧に復帰した. 測定回数 32 回の扔のおのを 分析すると, $30^{\circ}$ 頭位挙上にて血圧は, 上昇が 3 回, 不変 が 2 回, 残り 27 . 回は低下した. 日時を変えて複数回検査 を施行した 7 症例のうちで, $30^{\circ}$ 頭位挙上にて違った血圧 の変化を示す症例が 4 例であった。

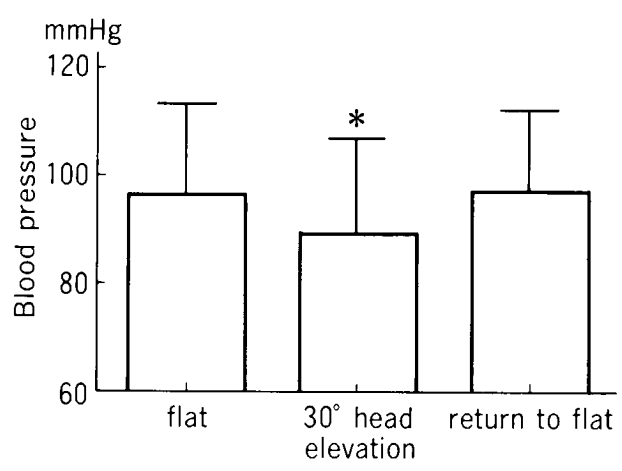

Fig. 2 At the haed elevation of $30^{\circ}$, the average blood pressure fell $96.5 \mathrm{mmHg}$ to $89.5 \mathrm{mmHg}$.

*The paired Student-T test showed the blood pressure change was statistical significant $(\mathrm{p}<0.01)$.

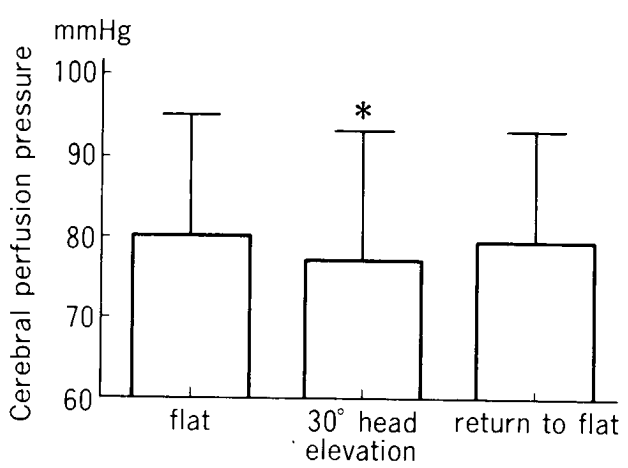

Fig. 3 At the head elevation of $30^{\circ}$, the average cerebral perfusion pressure fell $80.1 \mathrm{mmHg}$ to $77.3 \mathrm{mmHg}$.

*The paired Student- $T$ test showed the cerebral perfusion pressure change was statistical significant $(\mathrm{p}<$ $0.03)$.

\section{$330^{\circ}$ 頭位挙上の脳灌流圧に及ぼす影響}

水平位に打ける全測定例の脳灌流圧の平均值は 80.1 $\pm 14.90 \mathrm{mmHg}$ であったが, $30^{\circ}$ 頭位挙上にて $77.3 \pm 16.00$ $\mathrm{mmHg}$ と統計的に有意に低下し (paired Student-T test : $\mathrm{p}<0.03)$, 再び水平位にすると $79.4 \pm 13.70 \mathrm{mmHg}$ とほぼ元の脳灌流圧に復帰した (Fig. 3)。おの㧍のの測 定例を分析すると, 脳灌流圧上昇または不変が 12 回, 同 下降が 20 回であった. 日時を変えて複数回検査を施行し た 7 症例にうちで, $30^{\circ}$ 頭位挙上にて脳灌流圧が異なった 反応を示す症例が 3 例認められた。脳灌流圧上昇群（脳 灌流圧不変例 2 例を含む) と同下降群の水平位における 頭蓋内圧, 血圧, PVI をそれぞれ比較検定したが, Table 2 に示すごとく脳灌流圧上昇群で PVI が有意に低かっ た (unpaired Student-T test : $\mathrm{p}<0.03$ )。一方頭蓋内圧 および血圧は，脳灌流圧上昇群でやや高值を示したもの の, 同下降群との間で統計的有意差は認められなかった。 
Talbe 2 Comparison of each parameter at different CPP groups

\begin{tabular}{cccc}
\hline $\begin{array}{c}\text { Cerebral perfusion } \\
\text { pressure }(\mathrm{CPP})\end{array}$ & $\begin{array}{c}\text { Intracranical pressure } \\
(\mathrm{mmHg})\end{array}$ & $\begin{array}{c}\text { Blood pressure } \\
(\mathrm{mmHg})\end{array}$ & $\begin{array}{c}\text { Pressure Volume Index } \\
(\mathrm{m} l)\end{array}$ \\
\hline $\begin{array}{c}\text { Increased group }(\mathrm{n}=12) \\
\text { (Include unchanged case) }\end{array}$ & $17.2 \pm 4.55$ & $98.2 \pm 16.73$ & $16.6 \pm 4.54$ \\
Decreased group $(\mathrm{n}=20)$ & $17.2 \pm 5.63$ & $95.5 \pm 16.62$ & $20.6 \pm 4.78^{*}$ \\
\hline
\end{tabular}

* Statistical significant at $\mathrm{p}<0.03$ (unpaired Student-t test)

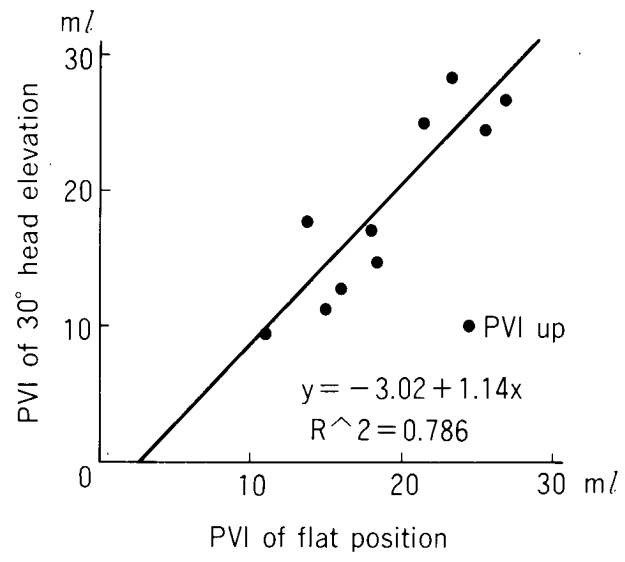

Fig. 4 PVI of $30^{\circ}$ head elevation correlates well to PVI of flat position suggesting that Pressure Volume Index (PVI) remains stable during position change.

\section{$430^{\circ}$ 頭位挙上の PVI に及ぼす影響}

水平位抢よび $30^{\circ}$ 頭位挙上の両体位で PVI が測定でき た 10 症例を比較検討した。水平位におけるPVI の平均 值は $19.1 \mathrm{~m} l$ であり，30頭位挙上における PVI の平均 值 $18.7 \mathrm{ml}$ と比較して有意差を認めなかった。さらに Fig. 4 に示すごとく，水平位における PVI をX軸に，30 頭位挙上における PVI をY軸にとり，それぞれのPVI 值を記入したところ，両者間で強い相関関係が認められ た（相関係数 $0.786 ）$.

\section{考 察}

\section{1 脳灌流圧測定の意義}

頭位挙上による頭蓋内圧の下降は実験的15)6720)にも 臨床的18)19121)24)にも確認されている.われわれの結果も 同様に，30頭位挙上で頭蓋内圧は有意に低下した．以上 より頭位挙上は明らかに頭蓋内圧を降下せしめる作用を 有しており，頭蓋内圧のみを考慮すれば，30頭位挙上は 非常に有用であると思われる。一方，脳灌流圧は頭蓋内 圧より患者の予後をよりよく反映し, 脳灌流圧が 40 $\mathrm{mmHg}$ 以下の患者は, 頭蓋内压の高低にかかわらず予後

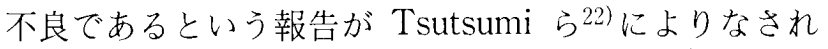

た.このため頭位挙上の影響を考慮するにあたり，頭蓋 内圧だけでなく脳灌流圧の変化も重要な事項として捉え られるようになってきた。

\section{2 睬灌流圧測定上の問題点}

各臓器における灌流圧は, 流入圧 (平均血圧) より流 出圧（平均静脈圧）を差し引いた值と定義されている。 脳灌流圧においては，頭蓋内圧が頭蓋内静脈圧とほぼ等 しいとの理由により，頭蓋内圧を頭蓋内静脈圧の代用と して使用している.すなわち脳灌流圧は次式で示される.

脳灌流圧 $=$ 平均血圧 - 平均頭蓋内圧 ${ }^{16)}$

われわれは側脸室内にカテーテルを挿入し，体位のい。 かんにかかわらず常にモンロー孔に水準点を置き, 側脳 室圧を測定し, これを頭蓋内圧とした。この方法は現在 最も信頼でき，かつ正確な頭蓋内压を反映しており，測 定上の問題は少ないと思われる. 一方流入圧としての血 圧は，末梢動脈である橈骨動脈を測定し，モンロー孔に 水準点を置くことにより, これを頭蓋内動脈圧として代 用している.しかしこの方法では頭蓋内動脈圧と末梢動 脈圧との違いを単なる静水压のみで補正しているため, 流入压としての頭蓋内動脈圧を正確に反映しているとは 思われない。

われわれの結果も示しているように，頭位挙上による 血圧の変化は各症例によりそれぞれ異なった変化を呈し ており, 単なる静水压のみでなく,より複雑な因子が関 与していることを示唆している：森山は頸動脈洞反射に よる CPP regulation mechanism の存在の可能性につ いて指摘し，高歯者ではこの CPP regulatory function が低下していると報告した ${ }^{13)}$ 。もしこのような regulation system が存在すれば, 頭位挙上時において末梢動 脈圧より算出した脳灌流圧は, 本来の脳灌流圧より低值 となる可能性が大きいと思われる. 正確な脳灌流圧を算 出するためには, 頭蓋内動脈圧を測定する必要があるが, これは常に可能ではなく, 時に危険を伴う. Woischneck ら ${ }^{23)}$ はこの問題点を考慮に入れて, 頭位挙上時の脳灌流 压の変化について研究し報告した。彼らは, 浅側頭動脈 圧と頭蓋底部の動脈圧は基本的に同一であることを示 
し，実際の臨床の場において正確な脳灌流圧を測定する ためには浅側頭動脈圧を測定し，これを頭蓋内血圧とし て代用し，脳灌流圧を算出することを勧好ている。また 彼らは浅側頭動脈圧と橈骨動脈などの未梢動脈圧では, 心臟に水準点を置いた場合，橈骨動脈などの末梢動脈圧 の方が浅側頭動脈圧より $12 \%$ ほど高いことを示し，両者 では単なる静水圧のみでは説明できない大きな違いがあ ることを指摘した．以上の問題点は脳灌流圧を測定する うえで重要な事項であり，結果を判定するにあたり十分 に考慮する心要があると思われる。

\section{3 重傷頭部外傷患者における $30^{\circ}$ 頭位挙上の有用性}

$30^{\circ}$ 頭位挙上時における頭蓋内压および血圧の低下は, 前述したように単なる静水圧に従うものではなく，他の 因子が関与していると思われる。このため頭位挙上時に おける脳灌流圧の変化もより多数の因子が関与してお り, 複雑なものとなっている.

われわれの結果を平均值のみで検討すると，頭位挙上 にて血圧は $7 \mathrm{mmHg}$, 頭蓋内圧は $4.4 \mathrm{mmHg}$ とそれぞ れ低下しており，血圧の低下が頭蓋内圧の低下ょり少し 大きいため, 結果的に脳灌流圧は軽度低下した。これは Rosner ら ${ }^{15)}$ の報告にほぼ一致しておう，平均值のみで みた結果では，頭位を水平に保つことが脳灌流圧を最大 に保つことになると思われる。しかし個々の検査を分析 すると，30頭位挙上にて脳灌流圧は上昇する例もあれ ば，低下する例もある．同一症例でも検査日時を変えて 複数回検査すると，脳灌流圧が異なった反応を示す例も あった。これは March ら ${ }^{8)}$ の報告と一致しており，最大 の脳灌流圧を得るためそれぞれ個々の症例に合った頭位 を取る必要があると思われる。

このように $30^{\circ}$ 頭位挙上において脳灌流圧は一定の動 向を示さずに変動するが，どのような症例において頭位 挙上が有用か予測することは, 治療上非常に重要である. $30^{\circ}$ 頭位挙上で脳灌流圧が上昇した群 (不変 2 例を含む) と下降した群に抢ける違いを，頭蓋内圧，血圧，PVI の 3 つのパラメータで比較したところ, 統計的に有意差を 認めたものはPVIのみであった。これはPVIすなわち 頭蓋内コンプライアンスが低い状態の症例では, $30^{\circ}$ 頭位 挙上にて頭蓋内圧の低下率が血圧の低下率より大きいた め, 脳灌流圧を低下させることなく頭蓋内圧を下げる可 能性が高いことを示している，頭位挙上にて頭蓋内圧が 低下するメカニズムは,以下の 2 つ理由が考えられる。

(1) 静脈還流の増加による頭蓋内血液量の減少3)15)

(2) 頭蓋内随液の脊髄内髄液腔への移動
これらにより総量としての頭蓋内 volume は頭位挙上に て減少するため，頭蓋内圧が低下寸る，また頭蓋内 vol一 ume の変化による頭蓋内圧の変化率は, PVI と密接な関 係にある10)。すなわち $30^{\circ}$ 頭位挙上における頭蓋内 vol一 ume の減少量が一定であれば, PVI の低い症例ほど著明 な頭蓋内圧の低下が招来され，その低下は血圧の低下を 上回るため脳灌流压が上昇するものと思われる。われわ れの結論としては，March らの報告と同様に，頭位挙上 による頭蓋内圧や脳灌流圧の反応を個々の症例で確認 し，それぞれの症例に合った頭位を適時取ることが望ま しいと考える。しかし実際の臨床の場に扔いて，常に頭 蓋内圧が測定できるとは限らない。このような状況下に おいては，画像診断にて tight brain の像を呈し，頭蓋 内コンプライアンスが低いと予想される症例に対して， 頭蓋内圧降下および脳灌流圧上昇に有効な $30^{\circ}$ 頭位挙上 が積極的に取り入れられるべきであると思われる。

\section{4] 30頭位挙上の頭蓋内コンプライアンスに及ほ す影響}

頭位挙上が頭蓋内コンプライアンスに及ぼす影響につ いて 2 つの報告がある. Ropper ら ${ }^{14)}$ は，volume tolerance test を利用して 19 例の患者の頭蓋内コンプライア ンスを測定し，頭位挙上において 5 症例，また頭位低下 において 4 症例で頭蓋内コンプライアンスの増加を認め たが,残りの 10 症例では頭位変換では頭蓋内コンプライ アンスは変化しなかったと報告している. Magnaesi は，頭蓋および脊髄腔を含めた全体のコンプライアンス は，体位変換ではほとんど影響を受けないと結論してい る.われわれの結果も頭位挙上と水平位ではPVI は変化 せず一定の值を呈しており，頭蓋内コンプライアンスの 測定方法に違いはあるものの, Ropper や Magnaes ら の報告と一致している。これは頭位挙上において頭蓋内 volume は減少するが，個々の压-容積曲線の特性は変え ないため, PVI は変化せず一定に保たれるためであると 考えられる. そして頭蓋内圧は頭蓋内 volume の変化に より同一の特性をもつた圧一容積曲線の上を移動し上下 する。しかし急激な頭位挙上で扁桃へルニアなどの craniospinal block が生じた場合，PVI が著明に減少す るので十分注意を払う必要がある。すなわち頭蓋内くも 膜下腔と脊髄くも膜下腔の間でブロックが存在する場 合，頭蓋内コンプライアンスは著明に低下する，Marmarou ら ${ }^{9)}$ は, 頭蓋脊髄腔コンプライアンスの compart. mental analysis を行い, 頭蓋内が全体のコンプライアン スの $68 \%$, 脊髄腔内が $32 \%$ をそれぞれ占めていると報告 している.このため完全な craniospinal block において, 
PVI は最大で $32 \%$ 減少する。われわれは今回の研究にお いてこのような症例は経験しなかったが, Magnaes らは 特に強い脳浮腫を伴う患者においては, orthostatic craniospinal block を防ぐため, $2 \sim 3$ 分かけてゆっく りと頭位挙上をすることを勧めている5゙．

\section{結 語}

1) PVI すなわち頭蓋内コンプライアンスの低い症 例では, $30^{\circ}$ 頭位挙上により頭蓋内圧の降下とともに脳灌 流圧は軽度上昇した。

2 ）頭蓋内コンプライアンスが水平位および $30^{\circ}$ 頭位 挙上位でどう変化するか, PVI を利用し比較したが, 頭 蓋内コンプライアンスは両頭位間で変化せず，ほぼ一定 の値を呈していた。

\section{文 献}

1) Bradley KC : Cerebrospinal fluid pressure. $J$ Neurol Neurosurg Psychiatry 33:387-397, 1970.

2) Durward QL, Amacher AL, Del Maestro RF, Ssbbald WJ : Cerebral and cardiovascular responses to changes in head elevation in patients with intracranial hypertension. J Neurosurg 59:938-944, 1983.

3) Gauer OH, Thron HL : Postural changes in the circulation, in Hamilton WF (ed) : Handbook of Physiology. Section 2, Vol 3, Baltimore, Williams \& Wilkins, 1965, pp. 2409-2439.

4) Kenning JA, Toutant SM, Saunders RL : Upright patient positioning in the management of intracranial hypertension. Surgical Neurology 15: 148-152, 1981.

5) Magnaes B : Body position and cerebrospinal fluid pressure. Part 1 : Clinical studies on the effect of rapid postural changes. $J$ Neurosurg 44:687-697, 1976.

6) Magnaes B: Movement of Cerebrospinal fluid within the craniospinal space when sitting up and lying down. Surg Neurol 10:45-49, 1978.

7) Magnaes B : Clinical studies of cranial and spinal compliance and the craniospinal flow of cerebrospinal fluid. Br. J Neurosurg 3:659-668, 1989.

8) March K, Mitchell P, Grady S, Winn R : Effect of Backrest Position on Intracranial and Cerebral Perfusion Pressures. J Neurosci Nurs 22 : 375-381, 1990.

9) Marmarou A, Shulman K, KaMorgese J : Compartmental analysis of compliance and outflow resistance of the cerebrospinal fluid system. J Neurosurg 43 : 523-534, 1975.

10) Marmarou A, Shulman K, Rosende RM : A nonlinear analysis of the cerebrospinal fluid system and intra- cranial pressure dynamics. J Neurosurg $48: 332-344$, 1978.

11) Maset AL, Marmarou A, Ward JD, Choi S, Lutz HA, Brooks D, Moulton RJ, DeSalles A, Muizelaar JP, Turner H, Young HF : Pressure-volume index in head injury. J Neurosurg 67:832-840, 1987.

12) McGraw C, Shields CB, Gamel JW, Greenberg RA : Impact of cerebral perfusion pressure on survival following head trauma. Intracranial Pressure VI. Berlin, Heidelberg, Springer-Verlag, 1986, pp. 667 $-670$.

13）森山光一：頭位変換時の脳循環調節におよぼす心血管系 の反応について。 日医大誌 56 ：258-266, 1989

14) Ropper AH, O'Rourke D, Kennedy SK : Head position, intracranial pressure, and compliance. Neurology (Ny) $32: 1288-1291,1982$.

15) Rosner MJ, Coley IB : Cerebral perfusion pressure, intracranial pressure, and head elevation. $J$ Neurosurg $65: 636-641,1986$.

16) Rosner MJ : Cerebral perfusion pressure :. Link between intracranial pressure and systemic circulation. Inwood JH (ed) : Cerebral Blood Flow: Physiologic and Clinical Aspects. New York, McGraw -Hill, 1987, pp. 425-448.

17) Rosner MJ, Daughton S : Cerebral perfusion pressure management in head injury. J Trauma $30: 933-941$, 1990.

18) Shalit MN, Umansky F : Effect of routine bedside procedures on intracranial pressure. Isr J Med Sci $13: 881-886,1977$.

19) Shapiro HM : Intracranial hypertension: Therapeutic and anesthetic considerations. Anesthesiology $43: 445-471,1975$.

20) Shucart WA, Connolly R: Experimental negative intraventricular pressures. J Surg Res 19:43-46, 1975.

21) Toole JF : Effects of change of head, limb and body position on cephalic circulation. $N$ Engl $J$ Med 279: 307-311, 1968.

22) Tsutsumi H, Ide K, Mizutani $T$, Takahashi $H$, Tanabe H, Kuroki H, Toyooka H, Mii K, Takakura K : The relationship between intracranial pressure, cerebral perfusion pressure and outcome in head-injured patients : The critical level of cerebral perfusion pressure. Intracranial Pressure VI. Berlin, Heidelberg, Springer-Verlag, 1986, pp. 661-666.

23) Woischneck D, Gaab RM, Rickels E, Heissler EH, Trost A : Correct measurement of cerebral perfusion pressure (CPP). Intracranial Pressure VII. Berlin, Heidelberg, Springer-Verlag, 1989, pp. 850-852.

24) Yoneda S, Matsuda M, Handa J, Handa H : Continuous measurement of intracranial pressure with SFT : Clinical experiences. Surg Neurol 4:289-295, 1975. 
重症頭部外傷患者管理における $30^{\circ}$ 頭位挙上の有用性 一特に頭蓋内コンプライアンスの低い症列において一

吉原 成哲 佐藤 潔 Anthony Marmarou

ICP (頭蓋内圧) 亢進をみる重症頭部外傷患者の管理に際し，CPP (脳灌流圧) を正常範囲内に維 持しつつICP を下降せしめることは重要な事項である. この問題と関連して, 患者の体位を頭部を 含め水平位とするか, あるいは頭位を $30^{\circ}$ 挙上すべきかを ICP と CPP の測定から比較梌討した. GCS 8 以下の重症頭部外傷患者 21 例を対象とした. ICP, 血圧そして CPPは頭位挙上で有意に 低下した. しかし測定回数 32 回のそれぞれを分析すると, CPP 上昇が 12 回, 同下降が 20 回であつ た. CPP 上昇群と同下降群の水平位における PVI (Pressure Volume Index) を比較したと こ3, CPP 上昇群で PVI ガ有意に低かった. 一般に頭位学上は CPP の低下を招くとされてきた が, PVIが低い状態では頭位挙上は ICP の下降と CPP の上昇を招来することが明らかにされた. 